\title{
Métodos para quebra da dormência das sementes de Leucaena leucocephala e Flemingia macrophylla
}

Morais, L.F. ${ }^{\circledR}$; Almeida, J.C.C.; Nepomuceno, D.D.; Abreu, J.B.R; Soares, F.A. e Silvestre, M.F.

Instituto de Zootecnia. Universidade Federal Rural do Rio de Janeiro. Seropédica. RJ. Brasil.

\section{PALAVRAS CHAVE ADICIONAIS}

Fixação biológica de Nitrogênio.

Leguminosas forrageiras.

Pastagens consorciadas.

\section{RESUMO}

Objetivou-se neste estudo avaliar métodos para efetuar a quebra da dormência de sementes de Flemingia macrophylla (flemíngia) e Leucaena leucocephala (leucena). As sementes foram submetidas aos tratamentos: a) Escarificação manual com lixa; b) Imersão em $\mathrm{H}_{2} \mathrm{SO}_{4} 98 \%$ durante cinco minutos; c) Imersão em $\mathrm{H}_{2} \mathrm{O}$ a $80^{\circ} \mathrm{C}$ durante 3 minutos; d) Pré-aquecimento a $60^{\circ} \mathrm{C}$ durante 150 minutos; e) Nitrato de potássio $\left(\mathrm{KNO}_{3} \mathrm{O}, 2 \%\right) ;$ f Ácido giberélico $\left.\left(\mathrm{AG}_{3} \mathrm{O}, 5 \%\right) ; \mathrm{g}\right)$ Controle (sem quebra de dormência). Para as sementes de flemíngia o tratamento $\mathrm{com}_{2} \mathrm{HO}_{4}$ obteve maior percentual de germinação, seguidos pela imersão em $\mathrm{H}_{2} \mathrm{O}$ à $80^{\circ} \mathrm{C}$ e escarificação manual com lixa. As sementes de leucena submetidas à imersão em água a $80^{\circ} \mathrm{C}$ e em $\mathrm{H}_{2} \mathrm{SO}_{4}$ apresentaram maior porcentagem de germinação com relação aos demais tratamentos. Assim, o emprego de água quente para as sementes de leucena e a imersão em $\mathrm{H}_{2} \mathrm{SO}_{4}$ para as sementes de flemíngia foram os métodos mais indicados para realizar a superação da dormência de suas sementes.

\section{Methods for overcoming seed dormancy of Leucaena leucocephala and Flemingia macrophylla}

\section{SUMMARY}

\section{AdDITIONAL KEYWORDS \\ Biological fixation of Nitrogen. \\ Leguminous forage. \\ Mixed pastures.}

INFORMATION

Cronología del artículo.

Recibido/Received: 28.01.2017

Aceptado/Accepted: 27.03 .2018

On-line: 15.04 .2018

Correspondencia a los autores/Contact e-mail:

leonardofiusa@yahoo.com.br

\section{INTRODUÇÃO}

A inclusão de leguminosas forrageiras em pastagens exclusivas de gramíneas é uma alternativa para promover o incremento da produção animal em sistemas pastoris, uma vez que, a leguminosa contribui para a sustentabilidade do sistema (Morais et al., 2017, p. 132). As plantas desta família possuem a capacidade de realizar a fixação biológica de nitrogênio atmosférico e fornecer para a gramínea em consorcio através de transferência direta, exsudação das células da raiz e decomposição de tecidos (Paynel et al., 2008, p. 282).
No entanto, a baixa germinação das sementes de leguminosas é um fator limitante a sua implantação em pastagens formadas com gramíneas. Isto acontece devido à dormência de suas sementes, promovida pela presença de um espesso tegumento impermeável à água, formado por uma camada de células de paliçada, cujas paredes celulares são espessas e cobertas por uma cutícula cerosa que, sob condições naturais, diminui a germinação das sementes (Morais et al., 2014, p. 1832).

A flemíngia (Flemingia macrophylla) e a leucena (Leucaena leucocephala) são leguminosas que apresentam diversos propósitos no meio pecuário, tais como: banco 
de proteína, legumineira, e por serem leguminosas de porte arbustivo-arbóreo, quando plantadas em pastagens, servem como local de refúgio e sombreamento, ofertando conforto térmico aos animais. Assim, a determinação de métodos eficazes e seguros de quebra da dormência das sementes destas leguminosas possibilitam maiores taxas de germinação, e aumenta as opções para seus empregos desta técnica pelos produtores rurais. Devido ao exposto, objetivou-se neste estudo avaliar diferentes métodos de quebra da dormência das sementes de flemingia e leucena.

\section{MATERIAL E MÉTODOS}

O estudo foi conduzido no Instituto de Zootecnia da Universidade Federal Rural do Rio de Janeiro (UFRRJ), no município de Seropédica, RJ, Brasil, no mês de outubro de 2012.

O delineamento experimental foi inteiramente casualizado com sete tratamentos e quatro repetições de 50 sementes. As sementes foram submetidas aos tratamentos: a) Escarificação manual com lixa; b) Imersão em $\mathrm{H}_{2} \mathrm{SO}_{4}$ a $98 \%$ por 5 minutos e posterior lavagem em água corrente; c) Imersão em água quente a $80^{\circ} \mathrm{C}$ por 5 minutos; d) Aquecimento a $60^{\circ} \mathrm{C}$ por um período de 150 minutos em estufa com circulação de ar; e) Germinação em substrato com Nitrato de potássio $\left(\mathrm{KNO}_{3}\right)$ a $0,2 \%$; f) Germinação em substrato com ácido giberélico $\left(\mathrm{AG}_{3}\right)$ a $0,5 \%$ g) Controle sem quebra de dormência.

As sementes de leucena foram distribuídas em caixas do tipo gerbox, providas de papel germiteste umedecido com água ou soluções de $\mathrm{KNO}_{3}$ e $\mathrm{AG}_{3}$. Para as sementes de flemíngia foi utilizada areia como substrato, de forma que a água e as soluções de $\mathrm{KNO}_{3}$ e de $\mathrm{AG}_{3}$ adicionadas na quantidade de $60 \%$ da capacidade de retenção do substrato. Após a aplicação dos tratamentos sobre as sementes, e distribuição destas as caixas, que foram colocadas em uma câmara de germinação do tipo BOD sem luz, a uma temperatura de $25^{\circ} \mathrm{C}$, segundo os protocolos descritos no Manual de Análise de Sementes do Ministério da Agricultura do Brasil (Brasil, 2009, p. 148).procedendo-se as avaliações no $7^{\circ}$ e $14^{\circ}$ dia, para determinação da proporção de sementes que produziram plântulas normais. Os resultados obtidos foram submetidos à análise da variância, quando significativos, realizando-se a comparação das médias pelo teste de Tukey a 5\% de probabilidade através do software Expdes do programa estatístico RStudio (Ferreira et al., 2013).

\section{RESULTADOS E DISCUSSÃO}

As sementes de flemíngia apresentaram 11\% de germinação quando submetidas ao tratamento controle, o qual não foi empregado nenhum método de quebra de dormência das sementes e 40,5\% de germinação com o tratamento empregando $\mathrm{H}_{2} \mathrm{SO}_{4}(\mathrm{P}<0,05)$. As sementes submetidas à imersão em $\mathrm{H}_{2} \mathrm{O}$ quente a $80{ }^{\circ} \mathrm{C}$ obtiveram $22,5 \%$ de germinação, entretanto não diferiu ( $\mathrm{P}>0,05)$ da escarificação manual com lixa com $20,5 \%$ de germinação. Os tratamentos com soluções de $\mathrm{KNO}_{3}, \mathrm{AG}_{3}$, aquecimento não diferiram entre si e apresentaram 12, 13,5 e 12,5\% respectivamente, e tam- bém não diferiram do tratamento controle $(\mathrm{P}>0,05)$. $\mathrm{O}$ que corrobora com os resultados obtidos por Salmi et al. (2008, p. 3), que obtiveram a maior porcentagem de germinação de sementes de flemíngia com o uso da técnica de imersão em $\mathrm{H}_{2} \mathrm{SO}_{4}$ em relação à água a $90{ }^{\circ} \mathrm{C}$.

Para leucena, o método de imersão de sementes em água a $80^{\circ} \mathrm{C}$ proporcionou $50,0 \%$ de germinação e com imersão em $\mathrm{H}_{2} \mathrm{SO}_{4} 46,0 \%$, não diferindo entre si $(\mathrm{P}>0,05)$. O tratamento controle proporcionou apenas $27 \%$ de germinação. Os tratamentos $\mathrm{KNO}_{3}, \mathrm{AG}_{3}$ e aquecimento não diferiram entre si e apresentaram 25,5, 19 e $16,4 \%$ respectivamente não diferiram estatisticamente do controle $(\mathrm{P}>0,05)$. Estes resultados corroboram com os encontrados por Telles et al. (2000, p. 389), que testou diferentes métodos para quebra da dormência de leucena, e obtiveram resultados com os tratamentos, imersão em $\mathrm{H}_{2} \mathrm{SO}_{4}$ concentrado por 20 minutos e imersão em água a $80{ }^{\circ} \mathrm{C}$ por 5 minutos. Deminices et al. (2006, p. 402), testaram a quebra da dormência de sementes de 8 leguminosas forrageiras tropicais submetidas a quatro métodos (Controle, água à $100^{\circ} \mathrm{C}$ por um período de $20 \mathrm{~min}$, escarificação manual com lixa e imersão em $\mathrm{H}_{2} \mathrm{SO}_{4}$ ), e obtiveram maiores taxas de germinação quando as sementes foram submetidas à imersão em água quente. Sementes submetidas a tratamentos térmicos em meio aquoso, aumentam sua germinação devido a maior velocidade de absorção de água e consequentemente, das reações bioquímicas que determinam todo o processo germinativo (Marostega et al., 2015, p. 446). Além do percentual de germinação, deve-se destacar para as duas espécies o uso de imersão em $\mathrm{H}_{2} \mathrm{O}$ a $80^{\circ} \mathrm{C}$ e a escarificação manual com lixa, devido à facilidade de acesso, condução e por apresentarem menores custos e riscos com acidentes para o produtor e em comparação ao uso da imersão em $\mathrm{H}_{2} \mathrm{SO}_{4}$.

\section{CONSIDERAÇÕES FINAIS}

Dentre os métodos apresentados, a imersão em $\mathrm{H}_{2} \mathrm{SO}_{4}$ durante 5 minutos é indicada para quebra da dormência das sementes de flemíngia, enquanto que, o uso da imersão em água a $80^{\circ} \mathrm{C}$ é o melhor para leucena, pois além da alta taxa de germinação é um método barato e com menor risco de acidente para o produtor.

\section{BIBLIOGRAFIA}

Brasil. Ministério da Agricultura, Pecuária e Abastecimento. Regras para análise de sementes / Ministério da Agricultura, Pecuária e Abastecimento. Secretaria de Defesa Agropecuária. -Brasília: Mapa/ ACS, 2009. 399 p.

Deminicis, B, Almeida, J, Blume, M, Araújo, S, Pádua, F, Zanine, A, e Jaccoud, C 2006. Superação da dormência de sementes de oito Leguminosas forrageiras tropicais. Archivos de Zootecnia, v. 55, no. 212, pp. 401-404.

Ferreira, E, Cavalcanti, P, Nogueira, D 2013. ExpDes.pt: Experimental Designs pacakge. R package (Português). version 1.1.2.

Marostega, T, Cuiabano, M, Ranzani, R, Da Luz, P, Sobrinho, S 2015. Efeito de tratamento térmico na superação de dormência de sementes de Passiflora suberosa L. Bioscience Journal, vol. 31, no. 2, pp. 445-450. 
Morais, L, Almeida, J, Deminicis, B, Padua, F, Morenz, M, Abreu, J, Araujo, R, Nepomuceno, D 2014. Methods for breaking dormancy of seeds of tropical forage legumes. American Journal of Plant Sciences, vol. 5, no. 13, pp. 1831-1835.

Morais, L, Almeida, J,Nepomuceno, D, Morenz, M, Deminicis, B, Carvalho, C, Silvestre, M 2017. Efeito da mastigação sobre a sobrevivência de sementes de leguminosas forrageiras tropicais e germinação. Archivos de Zootecnia, v. 66, no. 253, pp. 131-135.
Paynel, F., Lesuffleur, F, Bigot, J, Diquelou, S, Cliquet, J 2008. A study of $15 \mathrm{~N}$ transfer between legumes and grasses. Agronomy for Sustainable Development v. 28, no. 2, pp. 281-290.

Salmi, A, Guerra, J, Abboud, A, Lopes, H, Martelleto, M 2008. Superação da dormência das sementes de Flemingia macrophylla. Seropedica, RJ: Embrapa Agrobiologia, Comunicado técnico, no. 108, pp. 1-4. Telles, M, Alves, A, Oliveira, J, Bezerra, A 2000. Métodos para Quebra da dormência em Sementes de Leucena (Leucaena leucocephala). Revista Brasileira Zootecnia, vol. 29, no. 2, pp. 387-391. i 